\title{
Delimitation of Anxiety Disorder with Panic Attacks and Therapeutic Considerations for Approach
}

\author{
Dalaal Rosario Cruz López \\ Therapist and facilitator of refresher courses \\ Instituto de Estudios Superiores de Chiapas, Tuxtla Gutiérrez, \\ Chiapas, México
}

\begin{abstract}
One of the most acute mental health problems in recent years is anxiety disorders, where panic disorder is the most invalidating and suffering expression on the part of the sufferer. The research in this regard is extensive, from its causes and neurobiological expressions, through the pharmacology of its treatment and the usefulness of psychotherapy in the treatment and accompaniment of the patient. However, the divergences in the choice of psychotherapeutic current to use in these cases, makes it difficult to approach the theoretical causes of the problem, as well as the solution. This article aims to clarify the diagnostic and theoretical differences between panic disorders and other expressive disorders of pathological anxiety, in addition to conducting a longitudinal study of the treatment of patients diagnosed with severe anxiety, known as panic, with a humanist cutting therapy with cognitive-behavioral elements, finding their level of elevated efficacy, $80 \%$ of cases evaluated are resolved are resolved, in terms of remission of symptoms, in a time less than or equal to 10 months, assessing the patient's perception of the most useful intervention parts and the periodicity affordable for them.
\end{abstract}

Keywords:- Psychology, Anxiety, Panic Attacks, Psychotherapy, Anxiety Therapy.

\section{INTRODUCTION}

No mental health, no health. Mental illnesses decrease people's quality of life and compromise the development of them within various areas of life. Hence, providing knowledge to the area is significant, especially in the most frequent psychopathologies of today.

The World Health Organization, WHO (2017) estimates a presence of 260 million people with anxiety disorders, the Pan American Health Organization, PAHO (2013) found a prevalence in 2013 of $24.2 \%$ of the Population of the Americas with anxiety-related disorders.

The high incidence of this psychopathology is reflected in the reform carried out by the Senate of the Mexican Republic to article 72 of the General Health Law, regulating mandatory care in high-level centers to people with anxiety disorders and depression. This reform motivated by the presence of anxiety disorders in $14.3 \%$ of Mexican citizens, where $50 \%$ of cases occur before the age of 25 , in addition to being the mental health problem most

\author{
Bárbara Muñoz Alonso Reyes \\ Therapist TBE and Psychologist Professor \\ Public Health and Developmental Care Research Network, \\ REINVESAD
}

present in the population, above depression and addictions (Senado de la República, 2017).

Considering the statistics, two possibilities are expressed, one is the presence of cases that are not counted, and the second is the misdiagnosis that leads to increase the figures, no doubt both possibilities can be applicable in different cases and territories. One of the problems that contribute to a high statistical margin of error in the figures of anxiety problems comes from the theoretical elements, diagnoses that are especially confusing.

This problem starts from the delimitation of the concept, where the term "anxiety" seems diffuse, since some theoretical and regulatory aspects consider it an always pathological element, as in the case of the DSM-V, while various studies mark a distinction of this with fear, and place anxiety as an ever-present mechanism that may or may not tend towards pathological.

Anxiety can be defined as a state of nervous system activation, as a result of specific external stimuli, as a natural reaction to exalt the evaluative capabilities to the environment, defend the individual or predispose him for flight, involving the stimulation of the limbic system and cerebral cortex that translate into the psychological and somatic expressions of it (Martínez, et al, 2001).

There is an average level of anxiety that accompanies the human being in every situation, being the psychophysiological mechanism that allows a high level of attention to various stimuli, in addition to a protective function. It becomes anxiety when the stimulus triggers a psychological and physical reaction that exceeds the level. The above, considered as an expression of healthy anxiety.

Physical signs of a natural anxiety process include increased heart rate, blood pressure, increased blood flow to skeletal muscles and muscle tension, as well as feelings of alertness, psychological tension, or light distress. Anxious pathology is referred to when these symptoms occur in situations that do not require them, when they exceed a functional threshold, or when feelings of dizziness or nausea are associated, cold sweating, tremors not associated with physical cause, extreme distress, feeling of fading, feeling of closeness to death or madness, thus forming a disorder of the spectrum of anxiety (Stein and Hollander , 2006). 
In short, for this study, the use of the concept of anxiety is defined as a psychophysical expression that can be healthy, being a mechanism of defense and activation, with a harmless level constantly present in every individual, tending to a noticeable elevation before situations perceived as threatening, demanding or stressful, returning to their natural levels without visible complication. However, there is a pathological expression of this mechanism when the stimulus is not strong enough but produces symptoms, or even a stimulus absence triggers.

It is in this second expression that anxiety disorders typified in the International Classification of Diseases in their 10th edition (CIE-10) are concentrated by grouping them into two groups: 1) Phobic anxiety disorders, where agoraphobia, social phobias, specific phobias and others are included; and 2) the second group belonging to other anxiety disorders, encompassing panic disorder, generalized anxiety, mixed anxious-depressive disorder, and others (WHO, 2000).

It is in the second group where we find the most obvious and invalidating anxious disorder, for its symptoms and expressions, panic disorder. This consists of a period of anxiety too high and short-lived where physical symptoms are typically anxious are experienced at a high level, with high physical and mental suffering on the part of the patient. As a distinctive component, in addition to its duration, is the thoughts of closeness to death or losing control of oneself, produced by the same physical symptoms.

Hence the invalidating of this type of disorder, especially when panic attacks occur several times in the same day, causing significant wear and tear for the patient's body, mind, and emotions. It is not surprising that there is a significant degree of comorbidity of panic disorder with an expression of depressive disorders, as the patient tends to see panic attacks as uncontrollable, assimilating him to a sentence that presents himself when he least expects it, diminishing his confidence in self-control (Nardone, 2004)

Resuming PAHO statistics for anxiety disorders, expression in panic disorder is present in $1.8 \%$ of the population of the Americas, during 2013, and $0.9 \%$ in the Latin American population, during the same time. The above figures add to studies that reveal a high incidence of major depression associated with a panic disorder, where from a sample of 127 patients with panic attacks $6 \%$ had suicidal ideation, and in the case of patients with panic and depression the percentage of suicidal ideas reached $20 \%$ (Pilowsky, 2005)

The physical symptoms of the panic attack do not represent a real death violation, the psychological effects of the condition and its cognitive-emotional expressions if they may predispose to suicidal ideations in some cases, especially those with associated depression. Element of relevance, not only because of the increased suicide rate in recent years in pair with the increase in anxiety disorders, but also because of the relevance that these data bring to the perception of significant suffering caused by panic disorder.

With the above, it is clear the present difference between healthy anxiety and that represented by a pathology, this according to its degree of expression as well as the intensity of the causative stimulus. In addition to this, a period of pathological anxiety and a panic attack must be differentiated, among which the main difference lies in the time between the onset of symptoms and its peak, being shorter in the panic attack, a matter of minutes, and significantly longer in anxiety, being able to present the symptomatology for hours or even days (Arista , 2016).

The problem presented with the differentiation between diagnostic terms and methods has had as its fundamental consequence the excessive diversification of psychological methods and theories that support therapeutic intervention. Statistically, cognitive behavioral therapies are the most used, with mostly positive results for the patient, with no general statistics available. Cognitive behavioral intervention focuses on specific strategies within a therapeutic framework established by the therapist in individual, so its mixed use with other types of therapy is feasible and effective (Bornas et.al, 2002).

A booming therapy in Mexico is humanist cutting therapy, which, in terms of anxiety, conceives it as a process of anguish resulting from an emotional oppression and finds its possible origin in the stratum of psychoemotional development and realization of the individual, which is relatively inferior to its conception of the demands for the future (Sierra et.al , 2003).

Humanist psychology therefore addresses the understanding of psychopathology through the degree of personal development and the aspirations present in the individual, the cognitive distance between these elements and awareness of current abilities. Humanist therapy by including cognitive behavioral elements in the explanation of the problem represents a therapeutic style that can be mixed with cognitive elements for a more complete approach to a pathological anxiety process.

In addition to psychotherapy the use of psychopharmaceuticals is popular in the treatment of the disorder, benzodiazepines being the most used, followed by adrenergic receptor antagonists, and increasingly cases treated with SSRI antidepressants. The use of phytotherapy is also a viable alternative, especially the consumption of valerian and passiflorine (Benedi and Gomez, 2007)

In this respect it is vital to know the perceptions of patients regarding the experience in therapy, in addition to their verifiable effectiveness, to generate a firm and effective treatment line, both in the reduction of the symptom objectively, and in the overall experience of the patient. 


\section{METHOD}

The study was conducted with a qualitative cut divided into three phases during the period January to December 2019.

FIRST PHASE.- identification of cases of anxiety disorders and panic in the population No. 10 of patients who came to private consultation for symptoms of anxiety, in the city of Tonalá, Chiapas. Conducted by applying Beck's anxiety inventory (Beck et al, 1988), a widely used psychological test for the detection of symptoms of pathological anxiety and its severity.

SECOND PHASE. - Longitudinal monitoring of patients positive to anxiety, with mixed model psychotherapy, humanist therapy with elements of the cognitive current, during the period from January to December 2019. Resolved cases were quantified as unsolved cases.

THIRD PHASE.- In-depth interviews with longitudinal follow-up patients to assess their perception of therapy and the points that these patients find as most helpful during therapy throughout an annual follow-up.

\section{DISSCUTION}

$90 \%$ of the sample (n-10) had a degree of anxiety based on Beck's anxiety inventory.

$>$ According to the same inventory, $30 \%$ of the population encounters severe symptoms of anxiety, consistent with panic, $40 \%$ with moderate anxiety, $20 \%$ with low anxiety and the remaining $10 \%$ did not show a significant score for anxiety.

$>$ Of the total sample $90 \%$ consented to the therapeutic process for one year with the psychotherapeutic profile indicated above.

$>80 \%$ had a recovery in panic symptoms before 10 months, $10 \%$ represented a recovery over 10 months, and the remaining $10 \%$ showed no significant improvement per year of treatment.

$>$ The improvement was evaluated by decreasing or eradicating the symptoms presented by the patient related to perceptions and anxiety behaviors, through an in-depth interview.

> The psychotherapeutic tasks best evaluated by the patients in utility, were, in descending order: writing a story of any kind and sending it to 10 people to make a critique about it, writing the story through only thoughts identified as anxiety or panic attacks, aerobic physical exercise for 20 minutes a day.

> Regarding the periodicity of consultations, 30\% representative of panic attacks expressed preference for a weekly therapeutic periodicity over the fortnightly, $70 \%$ of the sample of anxiety representatives with other expressions, expressed in equal percentages the preference for weekly or fortnightly periodicity.

The results are found a significant incidence of panic attacks as an expression of pathological anxiety, as well as visualizing an initial tendency to go to professional mental health services when the symptoms present are evaluated as moderate anxiety according to Beck's anxiety inventory.

A high effectiveness of humanist cutting therapy with cognitive cutting tools was found, not only in the reduction of symptoms, but also in the time of remission, with an average of 10 months. This type of intervention includes written and restructuring tasks of perception of rejection and pathology on the part of the patient, which are evaluated as the most useful of therapy, with which they perceived an improvement.

An important point to highlight in the results obtained is the periodicity preferred by patients, possible element that contributes to the effectiveness of intervention, where a better symptomatologic and comfort reaction of the patient with therapy is highlighted if the sessions are weekly, especially in patients with panic disorder.

\section{CONCLUTIONS}

From a clear understanding of the diagnosed differences of healthy anxiety and pathological anxiety, in addition to the correct differentiation of anxiety episodes and panic attacks, an adequate visualization of a public health problem with high incidence rates and increasing trend is generated.

Although the choices in pharmacotherapy have a line of predilection for benzodiazepine treatment, in the case of the theoretical choice or psychotherapeutic current, adjuvant to the medication or independent to it, the line of predilection to anxiety disorders, specifically to panic disorders, becomes more diffuse.

This diversification, while valid in psychological practice, generates a lack of punctual help to a highly invalidating disorder with high psycho-emotional suffering, which together with the patient's own perception of "insurmountable" regarding panic attacks, can become harmful.

Global statistics give a preference in effectiveness to cognitive-behavioral interventions and strategic brief therapy, with the statistics of this second being the clearest in this regard, due to the diversity of cognitive behavioral statistics found.

Through a longitudinal study of patients in the area of Tonalá, Chiapas, within the private consultation is a significant effectiveness and appreciated by patients of techniques outside the office of cognitive-behavioral cut, which seem to be well suited to a therapy within humanist consultation.

In addition to the combined method of experiences induced with humanism and cognitive-behavioral tasks presented an effectiveness in the remission of symptomatology in a period less than or equal to 10 months a high percentage of the sample. 
This provides clarification on relatively rapid treatment for therapy standards, which give panic disorders a majorly positive and rapid recovery.

A timely recommendation is made to continue research within the framework of the effectiveness in symptoms and recovery time of panic attacks with techniques better valued by patients, to achieve a predominant line of work in cases of panic, which would help to visualize the problem as a pathology of rapid remission, and therefore, more confident in patients in their own recovery.

\section{REFERENCES}

[1]. WHO, Organización Mundial de la Salud (2017). "Informe la salud mental en el lugar de trabajo, en el marco del día mundial de la salud mental 2017" Recuperado https://www.who.int/mental_health/es/

[2]. PHAO, Organización Panamericana de la Salud (2013) "Estado de salud de la población: la salud mental en la región de las américas" Salud en las Américas $\quad+$, Recuperado de: https://www.paho.org/salud-en-las-americas2017/?post_t_es=la-salud-mental-en-la-region-de-lasamericas\&lang=es

[3]. Senado de la República (2017) "Boletín: 14.03\% de la población mexicana padece trastornos de ansiedad" Recuperado de: http://comunicacion.senado.gob.mx/index.php/inform acion/boletines/39699-14-3-de-la-poblacionmexicana-padece-trastornos-de-ansiedad.html

[4]. Martínez, P.A; Duran, A; Paredes, B. y Bousoño, M. (2001) "Manifestaciones clínicas de los trastornos de ansiedad" Editorial Masson. Barcelona, España.

[5]. Stein D y Hollander E. (2006) "Fenomenología del trastorno de angustia, en Tratado de los trastornos de ansiedad" Ars Médica. $1^{\text {a }}$ edición, Madrid España.

[6]. World Health Organization (2000) Guía de bolsillo de la [6] Clasificación Internacional de Enfermedades 10 Edición, CIE-10: Clasificación de los trastornos mentales y del comportamiento. Editorial Médica Panamericana. Madrid, España.

[7]. Nardone, G. (2004) "No hay noche que no vea el día: La terapia breve para los ataques de pánico" Versión en español por Editorial Harder. Barcelona, España.

[8]. Pilowsky, D (2005) "Pánico e ideas suicidas en adultos y adolescentes" Revista Medwave. Vol.5, Núm.6 DOI:10.5867/medwave.2005.06.2285

[9]. Arista, D. (2016) "La evolución del concepto de ansiedad: el sesgo atencional y su investigación actual" Trabaho final de grado en psicología COD.PS1048. Universitat de Jaume I. Recuperado del repositorio de la Universitat de Jaume I en http://repositori.uji.es/xmlui/handle/10234/164470

[10]. Bornas, X; Rodrigo, T; Barceló, F. y Toledo, M. (2002) "Las nuevas tecnologías en la terapia cognitivo-conductual: una revisión" Revista Internacional de psicología clínica y de Salud. Vol.2, No.2.
[11]. Sierra, J.C; Ortega, V. y Zubeidat, I. (2003) "Ansiedad, angustia y estrés: tres conceptos a diferenciar" Revista Mal-estar E Subjetividade. Vol.3, No.1. Brasil.

[12]. Benedí, J. y Gómez, M.A. (2007) “Ansiedad: tratamiento farmacológico y fitoterapéutico" Revista Farmacia Profesional. Espacio de Salud. Vol.21, Núm.1. España.

[13]. Beck, A. T., Epstein, N., Brown, G. y Steer, R. A. (1988). An inventory for measuring clinical anxiety: psychometric properties. Journal of Consulting and Clinical Psychology. 